\title{
The Analysis of Network Performance with Different Routing and Interconnection Methods
}

\author{
A. Kostic-Ljubisavljevic, S. Mladenovic, V. Acimovic-Raspopovic, A. Samcovic \\ Faculty of Transport and Traffic Engineering, University of Belgrade, \\ Vojvode Stepe 305, 11000 Belgrade, Serbia, phone: +38111 3091322, e-mail: a.kostic@sf.bg.ac.rs
}

\section{Introduction}

Following the liberalization of telecommunications markets worldwide, it became clear that the existing and new operators would find themselves in the situation through competing for their market position primarily by providing new services and obtaining ever-larger number of users. To achieve this, in economical way as possible, they need to interconnect with each other. Interconnection of telecommunications networks enables operators to provide numerous services to their end users. The main problem that arises in that situation is charging the service of interconnection. There are a very large number of approaches to solve this problem. The most common are cost-based, bill-and-keep, revenue sharing, retail minus...

Although mostly used approach is the cost-based as the fairest, since interconnection charges have only to cover costs, it has a big drawback - it is extremely difficult precisely to determine those costs. Regulatory agencies around the world created and implemented many different cost models [1]. One of them is the model created by the World Bank. That model requires a very large number of input parameters [2]. One of them is "routing factor", which represents the average number of times a network resource is used by the service considered. As a complete opposite of this approach, in the scientific and professional practice is proposed bill-and-keep approach, whose basic characteristics is that there are no charges between operators. The bill-and-keep method is the most appropriate in situations where the traffic between operators is in the balance. One of possible application is presented in [3]. Otherwise, one of the operators will have revenue losses because of greater traffic termination in its network. It is estimated that the bill-and-keep will have its application also in the next generation networks $[4,5]$.

Unlike the methods with fixed routing rules, dynamic routing is based on a different approach: traffic is assigned to those paths where the free links are available. Substantial savings in network investment costs can be achieved by choosing the appropriate dynamic traffic routing method. It allows better use of available resources.
In addition to savings, there are other advantages of the dynamic routing compared to fixed routing that are discussed in [6]. There are a very large number of different dynamic routing methods whose primary goal is to optimize the network performance by better utilization of its resources $[7,8]$. Shortest path routing is one of the most commonly used methods with application in various telecommunication networks [9]. One of many methods from the self-learning group is the last successful path routing and one of many applications is given in [10].

The basic hypothesis that we shall test in this paper is how various methods of dynamic routing of traffic can affect the performance of telecommunications network in which operate several telecommunications operators. Our research addressed the following dynamic routing methods: the shortest path routing - SPR; the three-hop routing (paths can contain only four nodes) - THR; the random path routing (paths are selected in a random way from the set of possible routing paths) - RPR and the last successful path routing - LSPR. In order to determine how properly selected combination of methods of dynamic routing and interconnection charging affects network performances, we have developed special software.

This paper consists of several sections. Firstly, the problem statement is given. After that, we will briefly describe software that we developed in order to obtain network performance analysis and the influence of routing and interconnection charging methods. The next section presents analysis of obtained results. Finally, some concluding remarks are given.

\section{Problem statement}

Let us consider the situation in which three telecommunication networks $\mathrm{A}, \mathrm{B}$, and $\mathrm{C}$ are interconnected as shown in Fig. 1. The network A consists of nodes 1, 2 and 4; the network B of nodes 3, 5, 6, 7 and 8 ; the network $\mathrm{C}$ of nodes 9 and 10 , and corresponding links respectively. Networks A and B are interconnected with links 4-7 and 4-6, while networks $B$ and $C$ with link $7-10$. For the purpose of network performance analysis, we 
applied four different routing methods in combination with two interconnection charging methods. The observed networks are characterized by: (1) the link capacity, (2) the link cost, (3) the node capacity, and (4) the node cost.

We assumed that all links in the network have equal capacity. The link cost is defined as the cost of the operator for carrying connection that is originated, transits through, or terminated in the network. In this paper, we introduce the "cost factor of interconnection". This factor multiplies the link cost in case when link is used for carrying traffic originated and terminated in interconnected networks. The node capacity is considered here as an average number of connection requests that can be generated at any node. The node capacity is normalized to one. If links entering and leaving the node are free, each node can forward all transit traffic. Each node is generating connection requests that are represented by Poisson traffic $[10,11]$, with a mean value as the multiple of pre-defined capacity of the node. We made software experiments with 10 possible values of multiple of offered traffic in interval $[0,5,5]$.

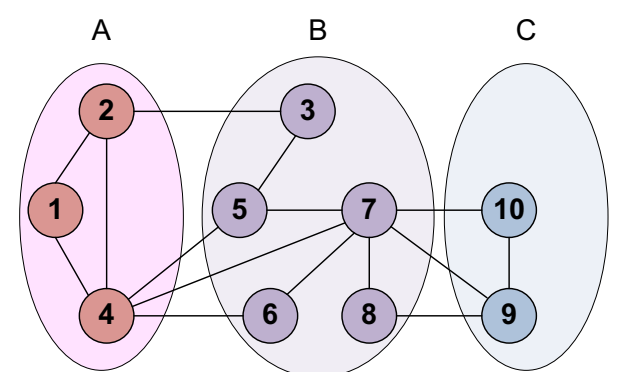

Fig. 1. Networks used in the analysis

The node cost is a parameter that represents the cost of forwarding connections through the observed node. Depending on a function of a given node, the cost can be related to generation, transition and termination of a connection. For all nodes, we defined that the costs of generating and termination of a connection are equal. The cost of transition is the half of generation/termination cost. The term connection here will be concerned as a subscriber request for bundle of services offered by operator. Customers are grouped around the observed nodes in the network. Bundle of services presents a group of selected broadband services. The term broadband access, which should be provided to each subscriber, means the permanent access to the resources of telecommunications networks with bit rates not less than $4 \mathrm{Mb} / \mathrm{s}$.

The period, which is seven times longer than the mean duration of connection, is simulated, while omitting from data analysis intervals that are equal to average duration of the connection at the beginning and end of the simulation. Duration of the connection is viewed as a random variable that has an exponential distribution.

\section{Software description}

Developed software provides the ability to perform a numerous of experiments and thus to obtain a large number of output data. It simulates the handling of traffic demands in the telecommunications network and performs statistical processing of the relevant parameters. In the structure of the software, which is schematically shown in Fig. 2, we can point out several logical units.

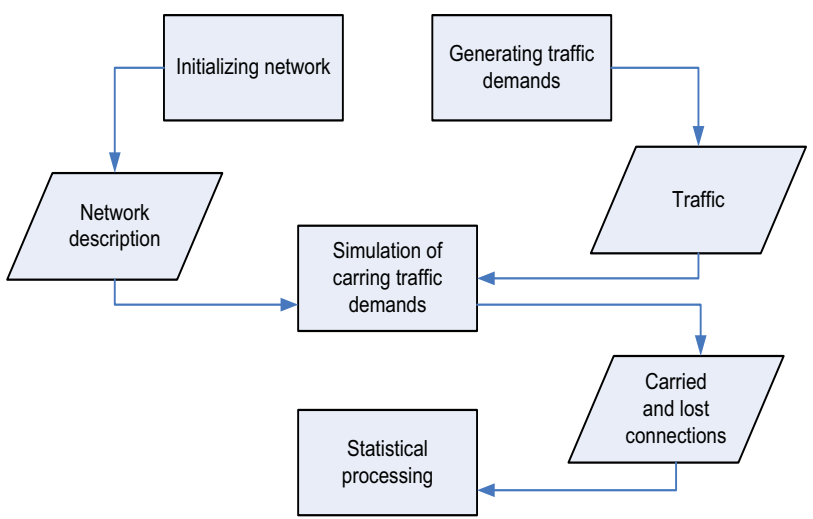

Fig. 2. Structure of the developed software

Initializing network. The telecommunications network is represented as a graph. Node attribute is the node capacity and link attributes are the start and end node as well as the link cost. The task of unit for initialization network is to represent the actual network by data structures suitable for the process of simulation.

Generating traffic demands. The parameter related to the intensity of traffic is entered from input mask, by choosing one of possible values between 0,5 and 5 .

Simulation of carrying traffic demands. For a given network and offered telecommunications traffic, the user selects one of the offered methods of routing and one of the offered interconnection charging methods. The process of simulation is activated after that. The connection can be carried or lost.

Statistical processing. It implies from the previous units giving the option of forming a number of statistics related to connections, nodes, links, paths, costs, and so on. All logical units described above have been implemented as program units in Microsoft Visual Basic 2005 environment. Because the software is modularly structured it can be extended with additional functions.

Simulation is performed in two separate phases. The traffic is generated in the network in the first phase, and it can vary with a factor of 0,5 to 5 . After generating the traffic, the desired routing method is chosen as well as interconnection charging method. In addition to these data the charging rate for the bundle of services can be chosen. Upon completion of the software procedure, relevant data are saved in the file. For each offered traffic, routing and interconnection charging method, and for each network, stored data are relating to:

- The number of connections that are generated, transited and terminated for each node, and for each network;

- Costs of connections;

- Percentage of link usage;

- Revenues obtained by carrying the connections;

- Number of connections that are originated/terminated in each network;

- Data about used paths (links, connections, usage time);

- Number of realized connections between node pairs;

- Cumulative and average costs of realized connections between node pairs. 
In order to get the correct information we need to run the software a sufficient number of times, and to make a proper statistical analysis of obtained results.

\section{Analysis of results}

In this section we will present one of the analysis which can be performed by processing the numerous data we obtained by multiple running of developed software. This analysis is about traffic balance in the observed networks (A, B and C). The traffic load of each link is observed in details, and in order to obtain the results more statistically valid, we calculated the mean value and standard deviation. The average load of all the links in the network is also calculated, as well as its deviation. It is observed that, with application of some routing methods, some links are unused while others are heavy loaded depending on applied routing methods and traffic intensity. With certain routing methods performance is better. Fig. 3 and Fig. 4 represent the dependence of percentage deviations from the average usage of links in the entire network for all routing methods, and both interconnection charging methods: bill-and-keep and cost based, respectively.

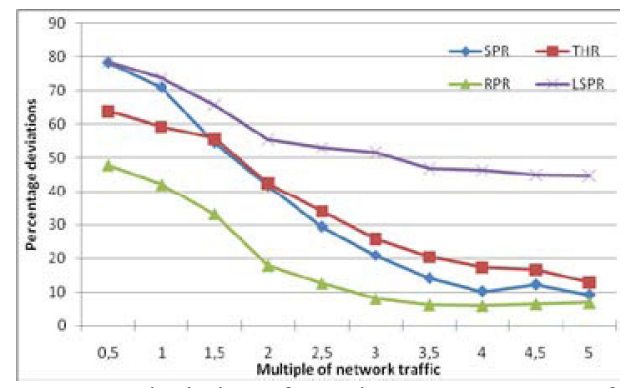

Fig. 3 Percentage deviations from the average usage of links for bill-and-keep approach

All four routing methods are observed in combination with two interconnection charging methods. As we have already pointed out, the traffic load balance is very significant for bill-and-keep interconnection charging, and the results obtained in this case will be further reviewed.

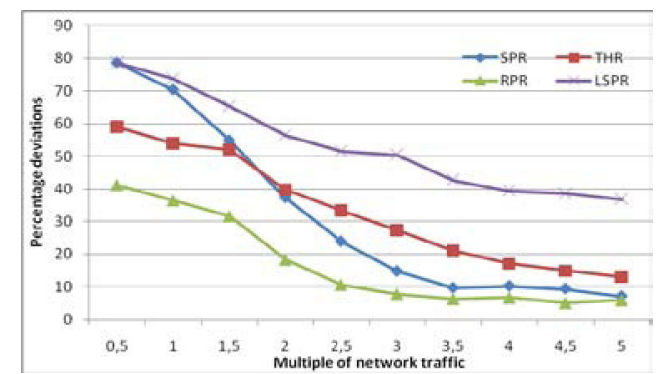

Fig. 4 Percentage deviations from the average usage of links for cost-based approach

It is observed for all routing methods that the traffic load balancing improves with increasing intensity of traffic in the network. Also, LSPR method gives unused links even at higher intensities of traffic, while some links are loaded with more than $90 \%$. An example of very low traffic balance, in case when offered traffic is multiplied with maximum value (5), is presented in Fig. 5.

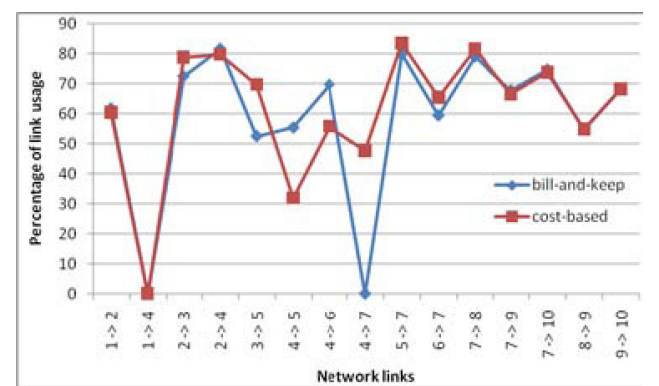

Fig. 5 Example of low traffic balance

In addition to this analysis, we looked at the balance of traffic in each network. It was turned out that the percentage deviation from the mean traffic load links in the observed part of the network depends on the intensity of traffic, and the selected routing method. In order to illustrate this fact, in Fig. 6 and 7 we will show examples of the very low and high traffic load, with the multiple of offered traffic equals 0,5 and 5 , respectively.

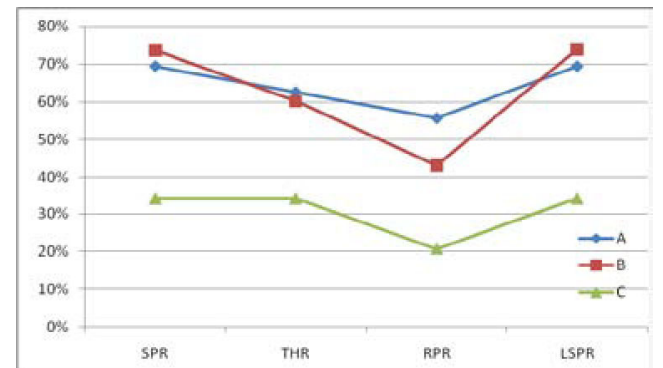

Fig. 6 Percentage deviations from the average usage of links for each network in case of very low traffic

It was observed that networks $\mathrm{A}, \mathrm{B}$ and $\mathrm{C}$ behave quite differently. The network $\mathrm{C}$ shows the best performance having the least deviation for all routing methods. Application of the LSPR method leads to the worst situation in terms of load balance. The Fig. 7 shows the case of the heaviest load in the network. A significant load balancing in all three networks can be noticed. The worst performance was also shown in this case by the LSPR method.

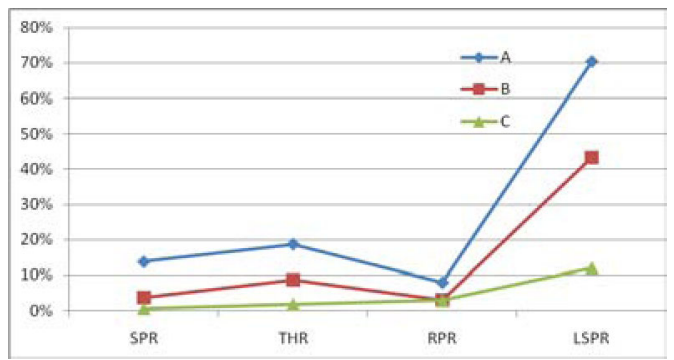

Fig. 7 Percentage deviations from the average usage of links for each network in case of very high traffic

\section{Conclusions}

In this paper the results of network performance analysis using the software developed for that purpose are shown. The aim of our research was to determine how routing and interconnection charging methods could influence network links load balance. Performed analysis showed very low interconnection charging method 
influence, but very significant routing method influence. LSPR method showed the lowest load balance performance in entire network, as well as in networks especially. The most appropriate routing method concerning traffic load balance is RPR. The balanced traffic load of all operators involved in the process is of crucial importance for the bill-and-keep interconnection charging method.

\section{Acknowledgements}

This work is partially supported by the Ministry of the Science and technological development of the Republic of Serbia contract No. TR-11013.

\section{References}

1. Armstrong M. Network Interconnections in Telecommunications // Economic Journal, 1998. - Vol. 108. - P. 545-564.

2. Kostić-Ljubisavljević A., Radojičić V., AćimovićRaspopović V. An Implementation of Adaptable Bottom-up Model for Calculation Interconnection Costs, // Proceedings of XLII ICEST 2007. - Ohrid, Macedonia, 2007. - Vol. 1. P. 177-180.

3. Lee J., Lee D. Bill and Keep as a Solution for Mobile-toMobile Interconnection of Korea, // Proceedings of 3rd ICCIT '08, 2008. - P. 197 - 205

4. Radojičić V., Kostić-Ljubisavljević A. Interconnection of next generation networks, // Proceedings of XXVII PosTel 2009. - P. 341-350.
5. Dodd M., Jung A., Mitchell B., Paterson P., Reynolds P. Bill-and-keep and the economics of interconnection in nextgeneration networks // Telecommunications Policy, 2009. Vol. 33. - P. 324-337.

6. Aćimović-Raspopović V., Kostić-Ljubisavljević A., Radojičić V. Dynamic Routing Design under Forecast Uncertainty // Proceedings of TELSIKS'2003. - P. 30-34.

7. Santos R. A., González-Potes A., García-Ruíz M. A., Edwards-Block A., Rangel-Licea V., VillaseñorGonzález L. Hybrid Routing Algorithm for Emergency and Rural Wireless Networks // Electronics and Electrical Engineering. - Kaunas Technologija, 2009. - No. 1(89). - P. 3-8.

8. Santos R. A., González A., García-Ruiz M., Edwards A., Villaseñor L., Rangel V. Analysis of Topological and Geographical Multicast Routing Algorithms on Wireless Ad Hoc Networks // Electronics and Electrical Engineering. Kaunas: Technologija, 2008. - No. 2(82). - P. 23-28.

9. Kwon S., Shroff N. B. Analysis of Shortest Path Routing for Large Multi-Hop Wireless Networks // Journal IEEE/ACM Transactions on Networking, 2009. - Vol. 17. - Iss. 3. - P. 857-869.

10. Chao D., Yong Z., Yinglei T., Zhang Z., Jiansong G. A self-learning multicast routing algorithm for multi-rate WiFi mesh network // Proceedinga of IC-BNMT'09, 2009. - P. 513-518.

11. Rindzevičius R., Tervydis P., Narbutaitė L., Pilkauskas V. Performance Analysis of Data Packet Transmission Network with the Unreliable Channels// Electronics and Electrical Engineering. - Kaunas: Technologija, 2008. - No. 4(84). - P. $53-58$.

Received 20100728

A. Kostic-Ljubisavljevic, S. Mladenovic, V. Acimovic-Raspopovic, A. Samcovic. The Analysis of Network Performance with Different Routing and Interconnection Methods // Electronics and Electrical Engineering. - Kaunas: Technologija, 2011. - No. 2(108). - P. 43-46.

The effects of dynamic traffic routing and interconnection charging methods on telecommunication network load balance are analyzed in this paper. The results of numerous simulations performed with software specially developed for analysis of network performances are given. It is shown that adequately chosen routing method can give good balancing of link loads which impacts the choice of networks interconnection charging agreement. Ill. 7, bibl. 11 (in English; abstracts in English and Lithuanian).

A. Kostic-Ljubisavljevic, S. Mladenovic, V. Acimovic-Raspopovic, A. Samcovic. Tinklo našumo analizė taikant skirtingus maršrutizavimo ir komutavimo būdus // Elektronika ir elektrotechnika. - Kaunas: Technologija, 2011. - Nr. 2(108). - P. 43-46.

Apžvelgiami telekomunikacijų tinkluose kintančiam duomenu srautui valdyti taikomi maršrutizavimo ir komutavimo būdai. Tinklo našumas nustatytas tam skirta programine iranga modeliuojant tinklo apkrovimą. Nustatyta, kad atitinkamai parinktus maršrutizavimo metodą galima gauti teigiamų rezultatų esant dideliai apkrovai ir įvertinant komutavimo būdus. Il. 7, bibl. 11 (anglų kalba; santraukos anglų ir lietuvių $\mathrm{k}$.). 